
1YY
H6

\section{UC-NRLF}

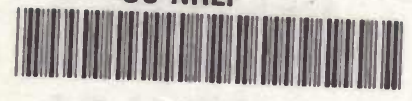
B 4570805 


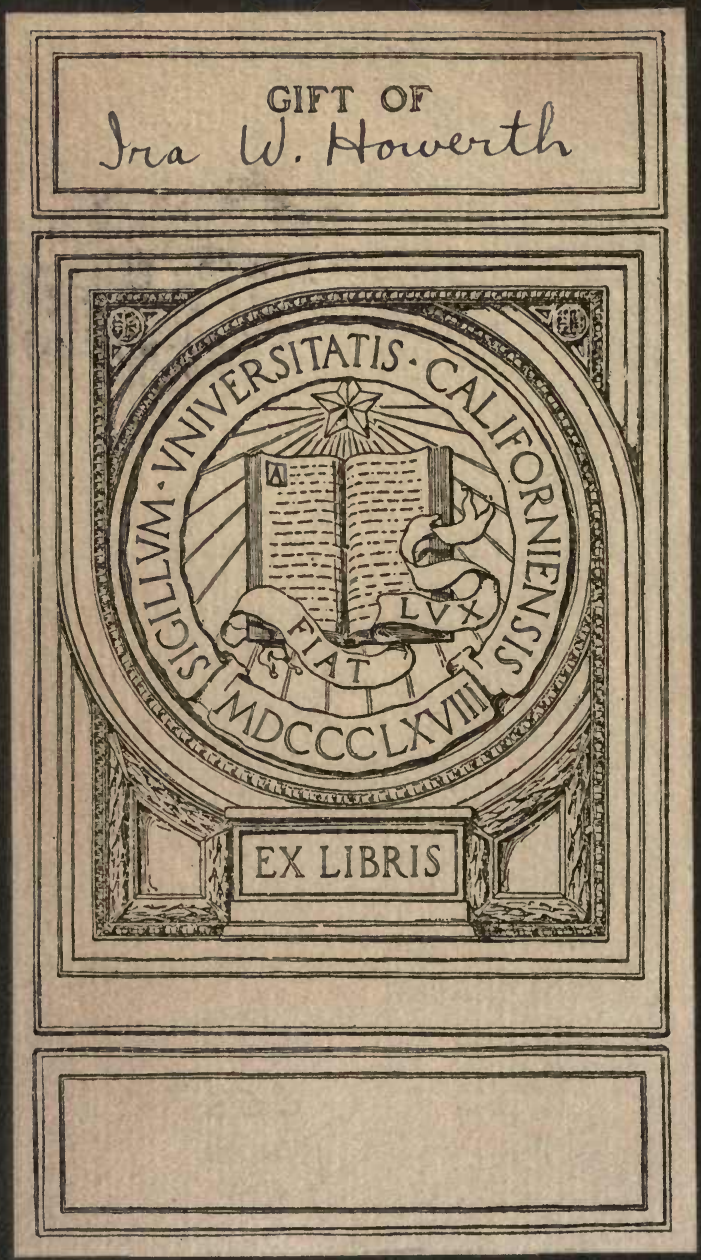




\section{THE CLASSIFICATION OF THE SCIENCES}

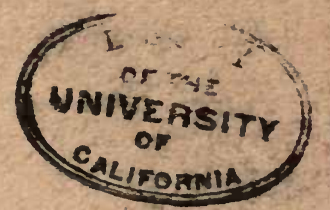

BY DR. IRA WOODS HOWERTH

$$
+
$$

Reprinted from the Popular Schence Monthly, August, 1911. 

[Reprinted from The Popular Scrence Monthly, August, 1911.]

\title{
THE CLASSIFICATION OF THE SCIENCES
}

\author{
BY DR. IRA WOODS HOWERTH \\ THE UNIVERSITY OF CHICAGO
}

THE sciences are divided by Spencer, Karl Pearson and others into 1 two great groups, the abstract sciences and the concrete sciences. The abstract sciences are those which deal with the modes under which the phenomenal world is perceived. They have to do entirely with the "relations of co-existence and sequence in their general or special forms." 1 Mathematics and logic are the two main branches of this division of the sciences.

It has been suggested by Comte, and insisted upon by Professor Lester F. Ward, ${ }^{2}$ that mathematics and logic are not true sciences, but merely "forms" or conditions of science and aids to its study. We need not here concern ourselres with this question. Our interest is rather in the classification of those sciences which deal with phenomena themselves rather than with the modes under which they are perceived, that is, the concrete sciences.

The classification of the concrete sciences may proceed, of course, from any one of a number of bases, as the chronological order of their development, their logical relationships, the evolution of their subject matter, etc. Bacon's classification is based upon three assumed faculties of our understanding-memory, imagination and reason; and Comte's classification rests upon the order in which the subject matter of the various sciences has been evolved. The latter is the basis of the classification we are about to propose.

The first consideration, then, must be the order in which the great natural groups of phenomena have manifested themselves in creation, that is, in the great erolutionary process.

Evolution has been described as that view of the universe which assumes that a vast, uniform, uninterrupted process of development obtains throughout all nature; and that all natural phenomena without exception, from the motions of the hearenly bodies and the fall of a rolling stone to the growth of plants and the consciousness of men, obey one and the same great law of causation. ${ }^{3}$ Science, to be sure, has

'Spencer, "The Classification of the Sciences," "Essays," Vol. III., p. 10.

"See Ward, "Dynamic Sociology," Vol. I., p. 106; also "Applied Sociology," p. 306.

'Haeckel, "Freedom in Science and Teaching," Chap. I. (Humboldt edition, p. 10). 
not yet closed up to the satisfaction of all the gaps in this process, but its " uninterrupted" character will hardly be denied by any one to whom this discussion will be of interest. We may assume that the principles of uniformity and continuity in evolution have been established.

Now the general process of evolution may be roughly divided into cosmic, organic and social; and it will not be denied that organic evolution has succeeded cosmic, and social evolution, organic. There are here presented, then, three great classes of phenomena in their genetic order; and not only that, but also three great divisions of the forces which occasion these phenomena, and three groups of sciences of which these phenomena are the subject matter. We shall now proceed to analyze the forces which produce these three kinds of evolution.

Cosmic, or inorganic, evolution involves three kinds of changesatomic, molecular and molar. There are accordingly in this department of evolution three sets of causes. These causes are forces to which we may ascribe the names atomic, molecular and molar. Changes which take place in the organic process are vital and mental; or, as we prefer to call them and the forces which give rise to them, biotic and psychic. The biotic forces are those which occasion the phenomena of life, and the psychic forces those which occasion the phenomena of mind. Finally, the phenomena of the social world must owe their causal relationships to forces which may be grouped under the general term social. We have, then, the forces of the phenomenal world analyzed into the atomic, the molecular, the molar, the biotic, the psychic, and the social forces.

It is important to observe that these various kinds of forces are not coeval, but have been successively brought into existence by the process described by Professor Ward ${ }^{4}$ as synergy. As a beginning of the evolutionary process, we may assume atomic attraction and repulsion, atomic collision, elective affinities-that is, atomic forces, and atomic forces only. Other forces had no existence in nature except as potency. It seems obvious enough that there could be no molecular forces until the molecule was built up, no molar forces until molecules were combined in masses, no biotic or vital forces until living matter was brought into existence, no psychic forces until mind appeared, and no social forces until the formation of the social group. Thus the various realms of forces here suggested are coeval and co-extensive with an equal number of great and well-defined fields of phenomena. No phenomena without change, no change without force. To these fields of phenomena we may now turn our attention.

To the changes of phenomena occasioned by atomic forces the name chemical is applied. Chemical change, so the books say, is one which

"See Ward, "Pure Sociology," p. 171 et seq. 
does not destroy the specific identity of a substance. To a change which does destroy this specific identity we apply the term physical. This is, of course, a narrow use of the term, but it is in accordance with past usage. Chemical phenomena are, then, the phenomena produced by chemical forces, and physical changes are those produced by molecular and molar forces. Chemical phenomena are first in order of time. "In the beginning" were atoms, atomic forces, atomic changes, chemism.

The second order of phenomena are the physical. They include the movements of molecules and masses from the invisible compounds of atoms to the great aggregates of matter in suns and stars. They are the natural outgrowth of chemical changes. Cooperating with the chemical forces the physical produced organic matter, protoplasm, and thus initiated the third great natural group of phenomena, the biological. Biological phenomena, which are the manifestation of the biotic forces, include, of course, the whole range of phenomena between inorganic nature and the origination of mind. Mind, we must assume, was also the creation of the preexisting forces, and the manifestations of mind, or psychic phenomena, constituted the fourth great division of phenomena. Finally, beginning with the origin of social groups, we have the constantly extending field of phenomena known as social, a direct manifestation of the social forces.

We have now presented a classification of forces and phenomena based on their genetic relationships. This, it will be observed, is equivalent to the classification of possible knowledge concerning concrete phenomena. It is thus a classification of the sciences. For a science is a study, or the classified knowledge resulting from the study, of a definite field of phenomena occurring in natural'sequence as a result of a particular set of forces. Our classification of forces and of phenomena in their genetic order is, then, in reality a serial or genetic classification of the subject matter of the sciences. "Sciences," says Ward, "in so far as they can be grouped at all, simply represent the natural groups of phenomena, and to determine the natural order in which phenomena are related to one another as indicated by their respective antecedence and sequence in the march of evolving forces, is to determine the natural order in which the sciences stand to one another." " The respective fields of forces and phenomena as already classified, then, imply corresponding sciences. There are five such fields, namely, chemical, physical, biological, psychological and sociological. Hence there are five great sciences: chemistry, physics, biology, psychology and sociology; and unless phenomena do not arise in the order stated above, this is a classification of the sciences which implies their genetic relationships and their relations of dependence. It is the order, too, of increasing

' "Dynamic Sociology,"' Vol. I., p. 147. 
complexity. The phenomena and forces of each science appear in all the sciences which succeed, but not in those which precede, it in the scale. Each science is thus engaged in the study of a new set of forces and phenomena. The order of the sciences here stated is, therefore, the order of increasing complexity and diminishing generality.

The foregoing classifications of the evolutionary process, forces, phenomena and sciences may be resumed in the following table:

\begin{tabular}{|c|c|c|c|}
\hline Evolution & Forces & Phenomena & Sciences \\
\hline Cosmic & $\begin{array}{l}\text { Atomic } \\
\text { Molecular } \\
\text { Molar }\end{array}$ & $\begin{array}{l}\text { Chemical } \\
\text { Physical }\end{array}$ & $\begin{array}{l}\text { Chemistry } \\
\text { Physics }\end{array}$ \\
\hline Organic & $\begin{array}{l}\text { Biotic } \\
\text { Psychic }\end{array}$ & $\begin{array}{l}\text { Biological } \\
\text { Psychological }\end{array}$ & $\begin{array}{l}\text { Biology } \\
\text { Psychology }\end{array}$ \\
\hline Social & Social & Sociological & Sociology \\
\hline
\end{tabular}

It is not necessary to contend or assert that the forces of the various fields of phenomena, and the consequent extent of the respective sciences are, or ever can be, as sharply defined as the foregoing discussion might seem to indicate. The possible overlapping of the fields of phenomena and the corresponding sciences should be indicated in the table by an arrangement of braces connecting them.

Chemistry, physics, biology, psychology and sociology are, then, the five great divisions in a comprehensive classification of the sciences. They are the five great stems or branches out of which all the other and more special sciences necessarily develop. There is no true science which may not be subsumed under one or the other of these general sciences.

Let us now compare the foregoing classification of the sciences with others, particularly those of Comte and Spencer. Comte's well-known "hierarchy" of the sciences includes the following: mathematics, astronomy, physics, chemistry, biology and sociology. Spencer includes in the concrete sciences astronomy, geology, biology, psychology, sociology and ethics. As already observed, Comte indicated a belief that mathematics is not a true science. It should also be noticed that he gave to biology a wider meaning than is ordinarily ascribed to it. He included what he called "transcendental biology," by which we may understand cerebral biology or psychology. He also, in his later writings, made ethics the final term of the series. His classification needs to be rearranged before a comparison is made. This rearrangement has been made by Professor Ward in a comparison of the classifications of Comte and Spencer. For convenience in comparison, we shall place the classification of Comte, Spencer and the one proposed in parallel columns: 
Comte's Classification
1. Astronomy
2. Physies
3. Chemistry
4. Biology
5. Cerebral biology
6. Sociology
7. Ethics

Spencer's Classification
1. Astronomy
2. Geology
3. Biology
4. Psychology
5. Sociology
6. Ethics

It will be observed that beginning with biology all three classifications are the same, with the exception that Comte and Spencer include ethics as a science coordinate with others of the group. If it properly belongs there it must have a special field of phenomena occasioned by a special set of forces coordinate with the social forces. But ethical forces and phenomena are occasioned by the social forces; hence ethics, as Professor Ward has pointed out, is only a department of sociology.

The chief difference between the proposed classification and those of Comte and Spencer lies in the divisions preceding biology. Astronomy with both Comte and Spencer is the first great division of the sciences. But to make astronomy the first of the sciences in a genetic classification is to imply that the subject-matter of astronomy is at the beginning of the creative process. Stellar phenomena, however, must have been preceded by both physical and chemical phenomena. Instead of being first and coordinate with other great sciences astronomy is properly a subdivision under physics. This is sometimes indicated by the application to astronomy of the names astro-physics, or celestial physics. Since it seems that stellar phenomena properly belong to the field of physics and chemistry, we are obliged to omit it from the classification as one of the great general sciences.

In Spencer's classification geology is placed second in the list. This is surely unwarranted. Geology, the study of the earth, is no more coordinate with chemistry, physics, biology, psychology and sociology than is the study of Venus, Mars or the moon. ${ }^{6}$ Geology, then, like the science of any other planet, properly belongs under astronomy.

The remaining and perhaps the most fundamental difference of the proposed classification from that of Comte is that in the former chemistry precedes physics. Bacon called physics the "mother of the sciences." Haeckel also, in the concluding chapter of his "Wonders of Life," speaks of physics as the fundamental science. In the fourth chapter of the same book, he writes as follows:

The study of the atoms and their affinities and combinations belongs to chemistry. As this province is very extensive and has its special methods of research, it is usually put side by side with physics as of equal importance; in reality, however, it is only a branch of physies-chemistry is the physics of the

'This is the opinion also of Professor Ward. See "Pure Sociology," p. 69, footnote.

voL. LXXIX. -12. 
atoms. Hence, when we speak of a physico-chemical inquiry or phenomenon we might justly describe it briefly as physical (in the wider sense).'

But "in the wider sense" all natural phenomena are physical. Thus we have the psychophysics of Fechner and Weber, and the social physics of Comte and Quetelet. Comte classed chemistry as one of the divisions of terrestrial physics, as if chemical phenomena were limited to the earth! In our classification we use the term physical in the narrow sense, and the science of physics is regarded as dealing with the molecular and molar movements of matter, that is, with physical changes no matter where they take place. These changes are preceded in the evolutionary process by the phenomena due to atomic affinities and combinations. Chemistry, therefore, should precede and not follow physics in a comprehensive genetic classification of the sciences. We thus make it first in the order of our classification, since its phenomena and forces are first in the order of time.

It would be interesting, perhaps, to continue farther an analysis of the sciences in order to show where some of the more familiar of the special sciences belong. Chemistry obviously falls into the two divisions, inorganic and organic. Physics may quite as obviously be divided into molecular and molar physics. The former division includes such sciences as thermology, electrology, etc., while under the latter, since it includes the study of all phenomena occasioned by the gravic forces, must necessarily fall such sciences as barology and astronomy, or at least that part of astronomy known as astrophysics. Geology, the science of the earth, a planet, belongs properly, as was said before, under astronomy. The general science of biology is the synthesis of four great special sciences, namely, protistology, phytology, zoology and anthropology. Psychology is individual and social. Finally, sociology should fall into the special sciences of the respective social groups, but the terminology is wanting. The special social sciences, as, for instance, history, politics, political economy, jurisprudence, etc., while they properly belong under sociology, are coordinate so far as the respective fields of their phenomena are concerned, and are consequently. not subject to arrangement on the basis of their own genetic relationships.

It would be difficult, however, if not impossible, to arrange diagrammatically the special sciences without cumbersome repetition, even if one possessed the requisite knowledge. Each branch of a science may be a contributor to a special science. Each division of biology, for instance, has its own morphological and physiological sciences. An attempt at such an arrangement, with existing scientific nomenclature, would involve extensive neologism.

'Haeckel, "The Wonders of Life," New York, 1905, p. 88. 
$\uparrow$ 
W. (3)

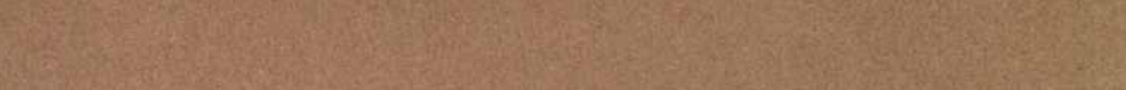

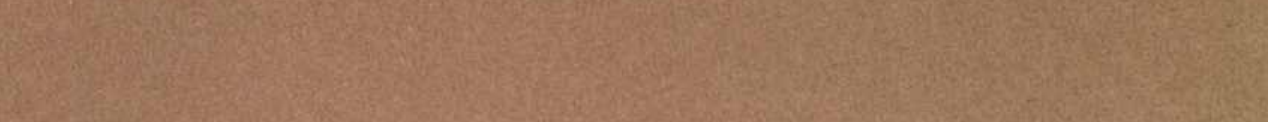

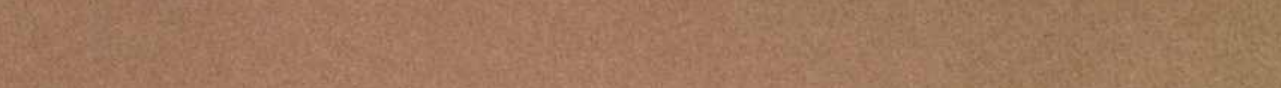

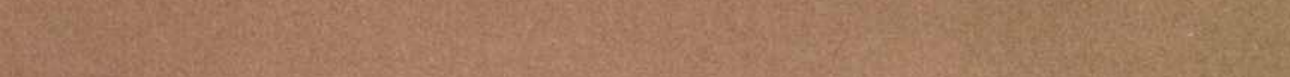
Not

20.0.

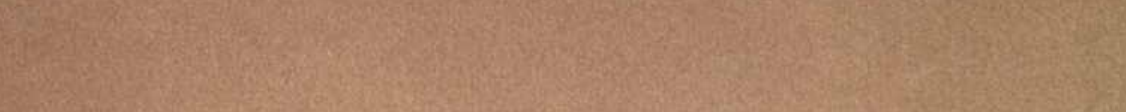

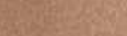





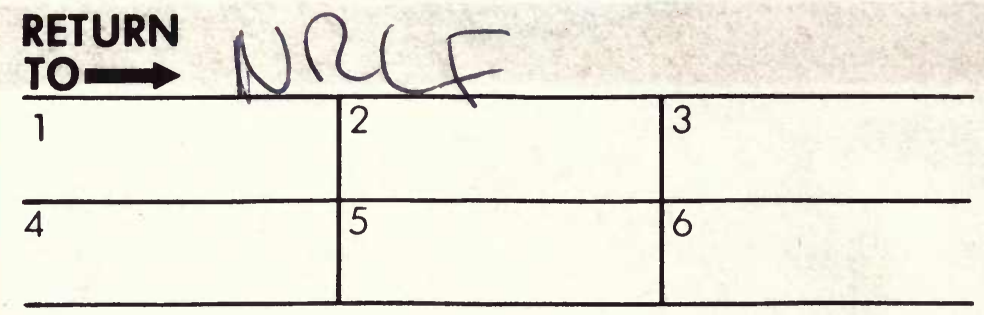

ALL BOOKS MAY BE RECALLED AFTER 7 DAYS

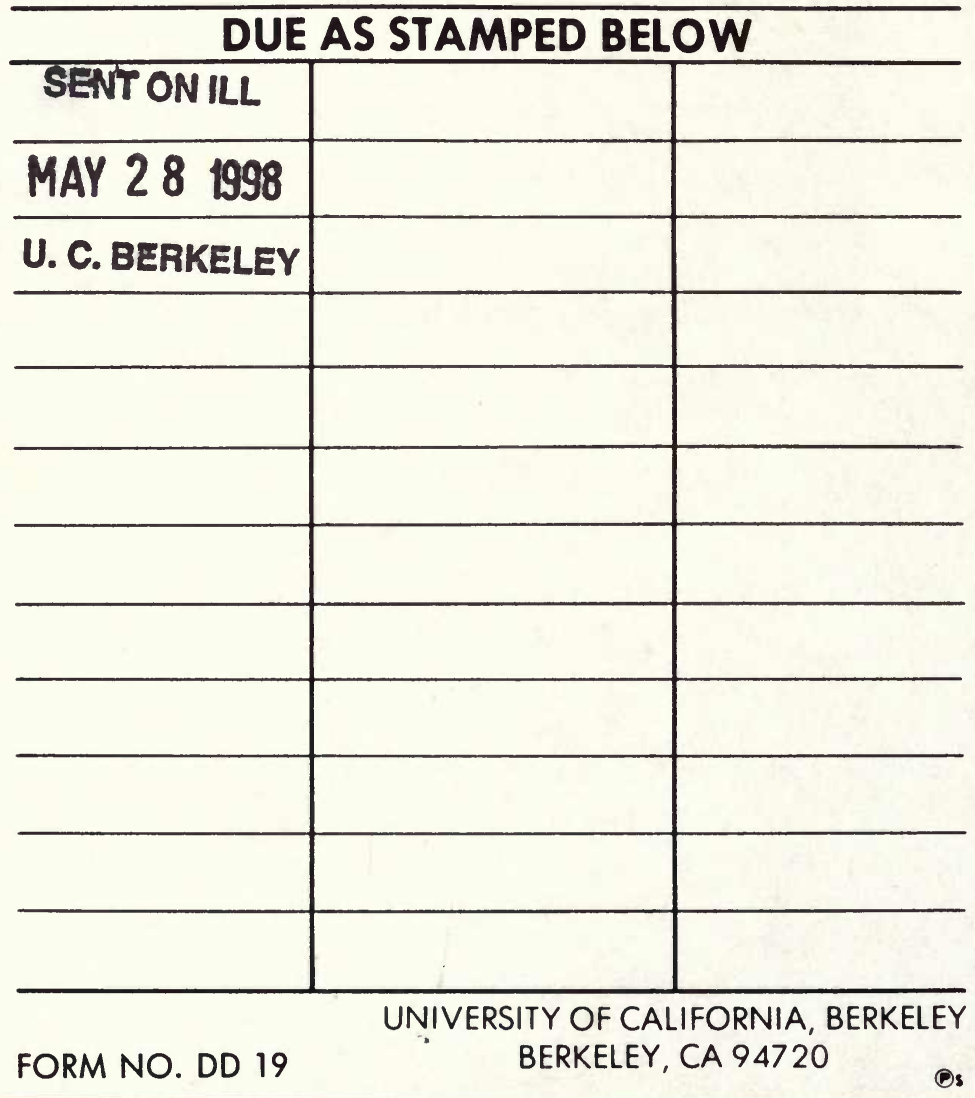




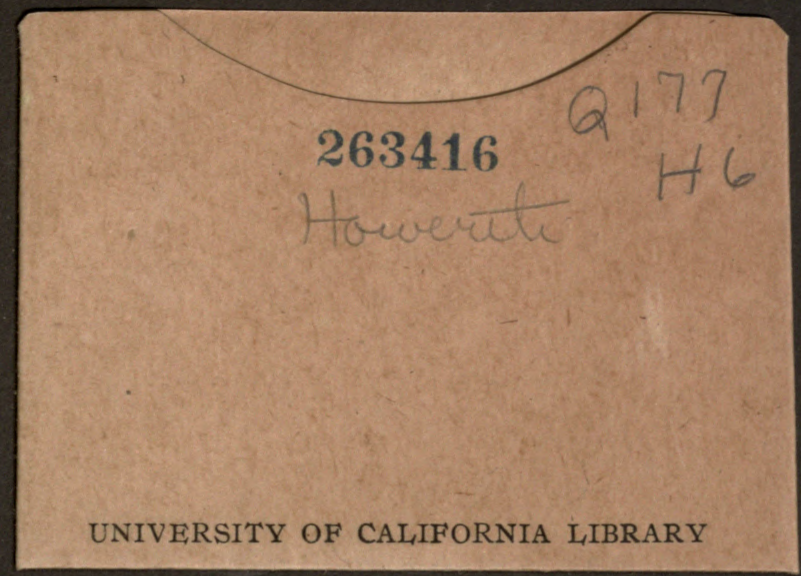


